\title{
PENGARUH BUDAYA SEKOLAH DAN MOTIVASI KERJA TERHADAP KOMITMEN GURU SMK DI KABUPATEN KEPULAUAN MERANTI
}

\author{
Tri Sofia Yanreta ${ }^{1)}$ \\ Zulfan Saam ${ }^{2)}$ \\ Makhdalena ${ }^{3)}$
}

\author{
1) Post Graduate Student of Riau University \\ 2) Lecturer of Education Management Study Programme PPs University of Riau \\ ${ }^{3)}$ Lecturer of Education Management Study Programme PPs University of Riau
}

\begin{abstract}
The purpose of this research is to know about the influence between variables (1) School Culture on work motivation of vocational teachers in SMK Kepulauan Meranti, (2) School Culture for vocational teachers' commitment in SMK Kepulauan Meranti, (3). Work Motivation, vocational teachers' commitment in SMK Kepulauan Meranti. The research method that used in this research is quantitative research methods. This research was carried out by spreading the instrument for 103 vocational school teachers in SMK Kepulauan Meranti. The collecting data has done by using a questionnaire. Analysis of the data was used to test the research hypothesis is path analysis with structural equation $X 2=\rho_{x 2 \times 1} X_{1}+\varepsilon_{1}$ and structural equation: $Y=$ $\rho_{y x 1} X_{1}+\rho_{y x 2} X_{2}+\varepsilon_{2}$. The results of this research indicate that accepted raised to be structural model . (1) School culture has a direct and significant effect on work motivation of teachers at 1,9\%. (2) School culture positively affects teachers' commitment amounted to 6,5\%. (3) Work motivation positive effect on the commitment of teachers at 18,5\%. The results of the study are expected to be useful for the repair and improvement of vocational teachers in the District's commitment Meranti Islands by way of school culture be used as guidelines to adapt to internal and external environment so that teachers have the motivation to work for the development of the school.
\end{abstract}

Keywords: School Culture, Work Motivation, Teachers' Commitmen. 


\begin{abstract}
ABSTRAK
Tujuan penelitian ini adalah untuk mengetahui tentang adanya pengaruh antar variabelvariabel (1) Budaya Sekolah terhadap Motivasi kerja guru SMK di Kabupaten Kepulauan Meranti, (2) Budaya Sekolah terhadap komitmen guru SMK di Kabupaten Kepulauan Meranti, (3). Motivasi Kerja terhadap komitmen guru SMK di Kabupaten Kepulauan Meranti. Metode penelitian yang digunakan adalah metode penelitian kuantitatif. Penelitian ini didapatkan melalui penyebaran instrument kepada 103 orang guru SMK di Kabupaten Kepulauan Meranti. Pengumpulan data dilakukan dengan menggunakan kuesioner. Analisis data yang digunakan untuk pengujian hipotesis penelitian adalah analisis jalur dengan Persamaan struktur : $\mathrm{X} 2=\rho_{\mathrm{x} 2 \times 1} \mathrm{X}_{1}+\varepsilon_{1}$ dan Persamaan struktur : $Y=\rho_{\mathrm{yx} 1} \mathrm{X}_{1}+\rho_{\mathrm{yx} 2} \mathrm{X}_{2}+\varepsilon_{2}$. Hasil penelitian menunjukkan bahwa model struktural yang diajukan diterima. (1) Budaya sekolah memiliki pengaruh langsung dan bermakna terhadap motivasi kerja guru sebesar 1,9\% (2) Budaya sekolah berpengaruh positif terhadap komitmen guru sebesar 6,5\%. (3) Motivasi kerja berpengaruh positif terhadap komitmen guru sebesar 18,5\%. Hasil penelitian diharapkan berguna bagi perbaikan dan peningkatan Komitmen guru SMK di Kabupaten Kepulauan Meranti dengan cara budaya sekolah dijadikan pedoman dalam beradaptasi dengan lingkungan internal maupun eksternal sehingga guru memiliki motivasi dalam bekerja demi kemajuan sekolah.
\end{abstract}

Kata Kunci : Budaya Sekolah, Motivasi Kerja, Komitmen Guru.

\section{PENDAHULUAN}

Untuk mengembangkan sekolah yang bermutu (berkualitas) dibutuhkan adanya lingkungan dan budaya sekolah yang kondusif,dinamis dan demokratis. Sebuah sekolah yang baik mempunyai budaya yang menjadi ruh di dalamnya. Sekolah memang akan berjalan dengan adanya siswa dan guru serta administrator yang melayani jalannya operasional sekolah, tetapi tanpa ruh sekolah hanya akan terjerumus menjadi sebuah organisasi tanpa arah. Sebuah budaya sekolah yang bisa dirasakan oleh individu yang ada didalamnya akan menjelma menjadi dasar pijakan pengembangan sekolah.

Dalam bekerja guru harus memiliki rasa tanggung jawab dan dedikasi yang tinggi terhadap pekerjaan itu sendiri maupun terhadap lingkungan pekerjaannya. Guru akan bekerja dengan penuh rasa tanggung jawab dan dedikasi yang tinggi jika memiliki komitmen organisasi.

Komitmen guru terhadap lembaga sekolah sebagai organisasi pada dasarnya merupakan suatu kondisi yang dirasakan oleh guru yang dapat menimbulkan perilaku positif yang kuat terhadap organisasi kerja yang dimilikinya.

Kabupaten kepulauan meranti yang saat ini sedang giat-giatnya membangun dan adanya komitmen pemerintah daerahnya untuk mengembangkan sumber daya manusia melalui dunia pendidikan berperan besar pada terciptanya budaya sekolah yang dapat meningkatkan bahkan mempertajam perhatian dan perilaku sehari-hari warga sekolah terhadap apa yang penting dan bernilai bagi sekolah . Kondisi ini tentunya merupakan salah satu faktor yang dapat menimbulkan 
motivasi kerja dan komitmen guru agar proses belajar dan mengajar dapat berjalan dengan lancar sesuai dengan tujuan yang ada.

Strum (1998) dalam Sopiah (2008:164) mengemukakan ada 5 faktor yang berpengaruh terhadap komitmen kerja, yakni: (1) budaya keterbukaan;(2) Budaya Sekolah ; (3) kesempatan personal; (4) arah organisasi; dan (5) penghargaan kerja yang sesuai dengan kebutuhan.

Motivasi kerja juga dapat mempengaruhi komitmen. Menurut Dessler (dalam Sopiah, 2008:159) ada beberapa cara yang bisa dilakukan untuk membangun komitmen pada organisasi diantaranya build valuebased homogeneity yaitu membangun nilai-nilai yang dibesarkan adanya kesamaan. Setiap anggota organisasi memiliki kesempatan yang sama misalnya untuk promosi maka dasar yang digunakan untuk promosi adalah kemampuan, keterampilan, minat, motivasi, kinerja, tanpa ada diskriminasi.

\section{METODOLOGI PENELITIAN}

Penilitian ini dilaksanakan di Sekolah Menengah Kejuruan (SMK) di
Kabupaten Kepulauan Meranti. Pelaksanaan penelitian ini mulai dilakukan pada bulan September 2015 sampai bulan November 2015. Populasi dalam penelitian ini adalah 138 orang guru. Dengan menggunakan rumus Slovin dengan nilai kritis (batas ketelitian) sebesar 5\% maka sampel dalam penelitian ini berjumlah 103 orang guru.

Teknik pengumpulan data dalam penelitian ini dengan melakukan penyebaran kuesioner (angket) untuk semua variabel. Analisis data yang digunakan dalam penelitian ini adalah analisis deskriptif dan inferensial. Analisis deskriptif menyajikan karakteristik data dari masing-masing variabel dalam bentuk penyajian data, ukuran sentral dan ukuran penyebaran data. Penyajian data ditampilkan dalam bentuk mean, median dan modus. Sedangkan ukuran sebaran disajikan dalam bentuk varians dan simpanagn baku. Analisis inferensial digunakan untuk menguji hipotesis yang telah dirumuskan. Analisis inferensial menggunakan analisis jalur (path analysis). Adapun model teoritik penelitian digambarkan seperti pada gambar 1 berikut :

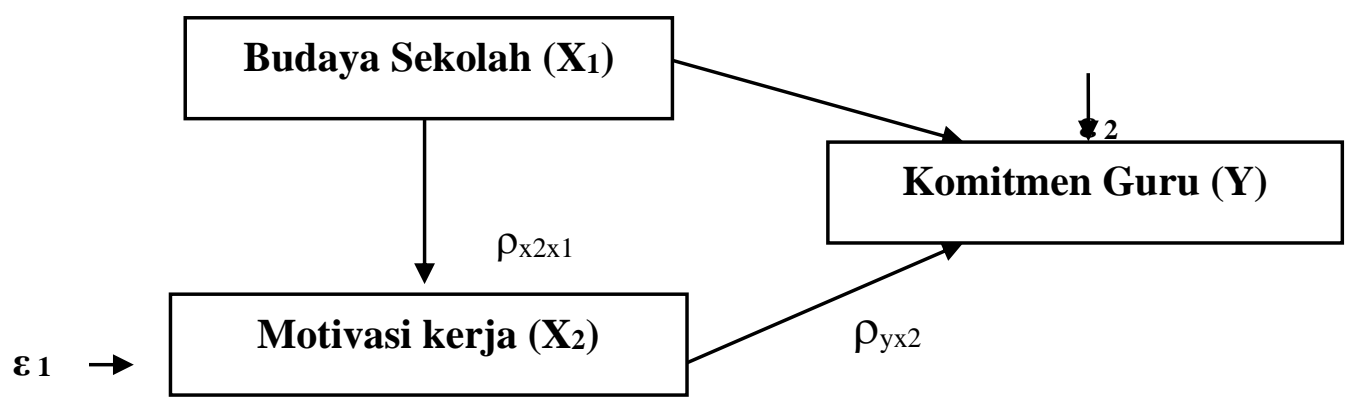

Gambar 1. Diagram jalur penelitian

Persamaan struktur : $\mathrm{X} 2=\rho_{\mathrm{x} 2 \times 1} \mathrm{X}_{1}+\varepsilon 1$

Persamaan struktur : $\mathbf{Y}=\rho_{\mathrm{yx} 1} \mathbf{X}_{1}+\rho_{\mathrm{yx} 2} \mathbf{X}_{2}+\varepsilon_{2}$ 


\section{HASIL PENELITIAN DAN PEMBAHASAN}

Sebelum dilakukan pengujian hipotesis, dilakukan uji signifikansi dan uji normalitas. Dalam penelitian ini terdapat tiga hipotesis yaitu 1) pengaruh budaya sekolah terhadap motivasi kerja, 2) pengaruh budaya sekolah terhadap komitmen guru, 3) pengaruh motivasi kerja terhadap komitmen guru.

\section{Pengaruh budaya sekolah terhadap} motivasi kerja

Pengaruh budaya sekolah terhadap motivasi kerja pada Tabel 1 berikut :

Tabel 1.Pengaruh budaya sekolah $\left(X_{1}\right)$ terhadap motivasi kerja $\left(X_{2}\right)$

\begin{tabular}{|l|l|l|l|c|}
\hline \multicolumn{1}{|c|}{ Variabel } & \multicolumn{1}{|c|}{$\begin{array}{c}\text { Koefisien } \\
\text { Jalur }\end{array}$} & Sig. & $\begin{array}{c}\text { Kesimpulan } \\
\text { Statistik }\end{array}$ & Pengaruh \\
\hline $\begin{array}{l}\text { Budaya } \\
\text { Sekolah }\left(\mathrm{X}_{1}\right)\end{array}$ & 0,138 & 0.00 & $\begin{array}{c}\text { Signifikan } \\
\text { (Ho ditolak) }\end{array}$ & $1,9 \%$ \\
\hline $\mathrm{R}^{2}=0.019$ & $\mathrm{~F}=1,958$ & \\
$\mathrm{t} \quad=1.399$ &
\end{tabular}

Koefisien jalur pada sub struktur 1

Persamaan struktur : $\mathbf{X} \mathbf{2}=\rho_{\mathbf{x} 2 \times 1} \mathbf{X}_{1}+\varepsilon \mathbf{1}$

Dari hasil pengolahan data program SPSS versi 17 pada substruktur 1. Terlihat bahwa pada kolom signifikan pada tabel 1 sub-struktur 1 didapat nilai sig 0,000 . Nilai sig $0,000<$ 0,05, maka Ho ditolak dan Ha diterima, artinya budaya sekolah berpengaruh signifikan terhadap motivasi kerja.

Berdasarkan hasil analisis pada tabel 1 diperoleh koefisien jalur $\mathrm{X}_{1}$ terhadap $\mathrm{X}_{2}\left(\mathrm{Px}_{2} \mathrm{X}_{1}\right)=0,138, \rho \mathrm{X}_{2} \mathrm{X}_{1}=$ Beta $=0,138(\mathrm{t}=1,399$ dan probabilitas $(\operatorname{sig})=0,000)$

Pada tabel 1 dapat diketahui nilai koefisien determinan atau pengaruh $(\mathrm{R}$ square $)=\mathrm{R}^{2}$ variabel budaya sekolah terhadap motivasi kerja sebesar 0,019. Angka ini menunjukkan bahwa pengaruh variabel budaya sekolah $\left(\mathrm{X}_{1}\right)$ terhadap motivasi kerja $\left(\mathrm{X}_{2}\right)$ secara simultan adalah $1,9 \%$. Sementara sisanya sebesar 98,1\% dipengaruhi faktor lain.

Berdasarkan hasil analisis adapun nilai koefisien determinan atau pengaruh $(\mathrm{R}$ square $)$
$=\quad 0,019 . \quad$ Besar koefisien residu $\varepsilon_{1}=$ $=0,990$ dengan demikian didapat diagram jalur sub- struktur 1 seperti gambar 1 dan persamaan struktur -1 sebagai berikut. 
Struktur $-1: \mathrm{X}_{2}=\rho \mathrm{x}_{2} \mathrm{X}_{1} \mathrm{X} 1+\rho \mathrm{x}_{2} \varepsilon_{1}$

dan $R^{2} \mathrm{x}_{2} \mathrm{X}_{1}=0,138 \mathrm{X} 1+0,990 \varepsilon_{1}$ dan

0,019

a. Pengujian secara simultan (keseluruhan)

Dari hasil pengolahan data program SPSS pada sub-struktur 2 tersebut terlihat pada tabel 2 koefisien

2. Pengaruh budaya sekolah dan motivasi kerja terhadap jalur diperoleh sebagai berikut komitmen guru

Tabel 2.Pengaruh budaya sekolah $\left(X_{1}\right)$ dan motivasi kerja $\left(X_{2}\right)$ terhadap komitmen guru (Y)

\begin{tabular}{|l|l|c|c|c|}
\hline \multicolumn{1}{|c|}{ Variabel } & \multicolumn{1}{|c|}{$\begin{array}{c}\text { Koefisien } \\
\text { Jalur }\end{array}$} & Sig. & $\begin{array}{c}\text { Kesimpulan } \\
\text { Statistik }\end{array}$ & Pengaruh \\
\hline $\begin{array}{l}\text { Budaya } \\
\text { Sekolah }\left(\mathrm{X}_{1}\right)\end{array}$ & 0.256 & 0.04 & $\begin{array}{c}\text { Signifikan } \\
\text { (Ho ditolak) }\end{array}$ & $6,5 \%$ \\
\hline $\begin{array}{l}\text { Motivasi } \\
\text { Kerja }\left(\mathrm{X}_{2}\right)\end{array}$ & 0.431 & 0.00 & $\begin{array}{c}\text { Signifikan } \\
\text { (Ho ditolak) }\end{array}$ & $18.5 \%$ \\
\hline $\mathrm{R}^{2}=28.2 \%$ & $\mathrm{t}(\mathrm{X} 1)=2.989$ & \\
$\mathrm{~F}=19.612$ & $\mathrm{t}(\mathrm{X} 2)=5.039$ & \\
\hline
\end{tabular}

Koefisien jalur pada sub struktur 2

Persamaan struktur : $\mathbf{Y}=\rho_{\mathbf{y x} \mathbf{1}} \mathbf{X}_{1}+\rho_{\mathbf{y x} 2} \mathbf{X}_{2}+\varepsilon_{2}$

Besarnya pengaruh secara simultan dapat dilihat pada tabel diatas bahwa nilai koefisien determinasi $\mathrm{R}^{2}$ sebesar $28.2 \%$. nilai ini menunjukkan bahwa pengaruh secara bersama sama variabel budaya sekolah $\left(\mathrm{X}_{1}\right)$ dan motivasi kerja $\left(\mathrm{X}_{2}\right)$ terhadap komitmen guru (Y) adalah sebesar $28.2 \%$ dan selebihnya dipengaruhi oleh factor factor lain diluar variabel yang diteliti.

Dari tabel 2 diperoleh nilai $\mathrm{F}$ sebesar 19,612 dengan nilai probabilitas $($ sig $)=0,000$, karena nilai sig $<0,05$ maka keputusan adalah Ho ditolak, artinya Budaya sekolah dan motivasi kerja berpengaruh secara simultan dan signifikan terhadap komitmen guru. Dengan demikian pengujian secara individu dapat dilakukan atau dilanjutkan

\section{b. Pengujian secara individual sub-} struktur 2

a. Budaya sekolah berpengaruh secara signifikan terhadap komitmen guru.

Terlihat bahwa pada kolom signifikan pada tabel 2 sub-struktur 2 
didapat nilai sig 0,004 . Nilai sig $0,004<$ 0,05, maka Ho ditolak dan Ha diterima, artinya budaya sekolah berpengaruh signifikan terhadap komitmen guru.

\section{b. Motivasi Kerja berpengaruh} signifikan terhadap komitmen guru Terlihat bahwa pada kolom signifikan pada tabel 2 sub-struktur 2 didapat nilai sig 0,000. Nilai sig 0,000 < 0,05, maka Ho ditolak dan Ha diterima, artinya motivasi kerja berpengaruh secara signifikan terhadap komitmen guru

Berdasarkan hasil analisis jalur sub-struktur $2\left(\mathrm{X}_{1}, \mathrm{X}_{2}\right.$, dan $\left.\mathrm{Y}\right)$ yang terlihat pada tabel 2 masing-masing diperoleh nilai:

a. $\quad$ $\mathrm{X}_{1}=$ beta $=0,256(\mathrm{t}=2,989$ dan probabilitas sig $=0,004)$ b. $\quad \rho y X_{2}=$ beta $=0,431(t=5,039$ dan probabilitas sig $=0,000$ )

Besarnya koefisien determinan (pengaruh) $\mathrm{X}_{1}$ dan $\mathrm{X}_{2}$ secara simultan terhadap Y sebesar:

Rsquare $=0,282$ Besar koefisien residu $\quad \varepsilon_{2}=0,847$.

Berdasarkan hasil dari diagram jalur sub-struktur 2 seperti gambar 1 , maka kerangka hubungan kausal empiris antar variabel $\mathrm{X}_{1}$ dan $\mathrm{X}_{2}$ terhadap $\mathrm{Y}$ dapat dibuat melalui persamaan struktur sebagai berikut:

Sub - Struktur - $2: \quad \mathrm{Y}^{\prime} \rho \mathrm{yx}_{1} \mathrm{X}_{1}$ $+\rho \mathrm{yx}_{2} \mathrm{X}_{2}+\rho \mathrm{y} \varepsilon_{2}$ dan $R^{2} \mathrm{y} \mathrm{x}_{2} \mathrm{X}_{1}$

$$
=0,256 \times 1+
$$

$0,431 \times 2+0,847$ dan 0,282

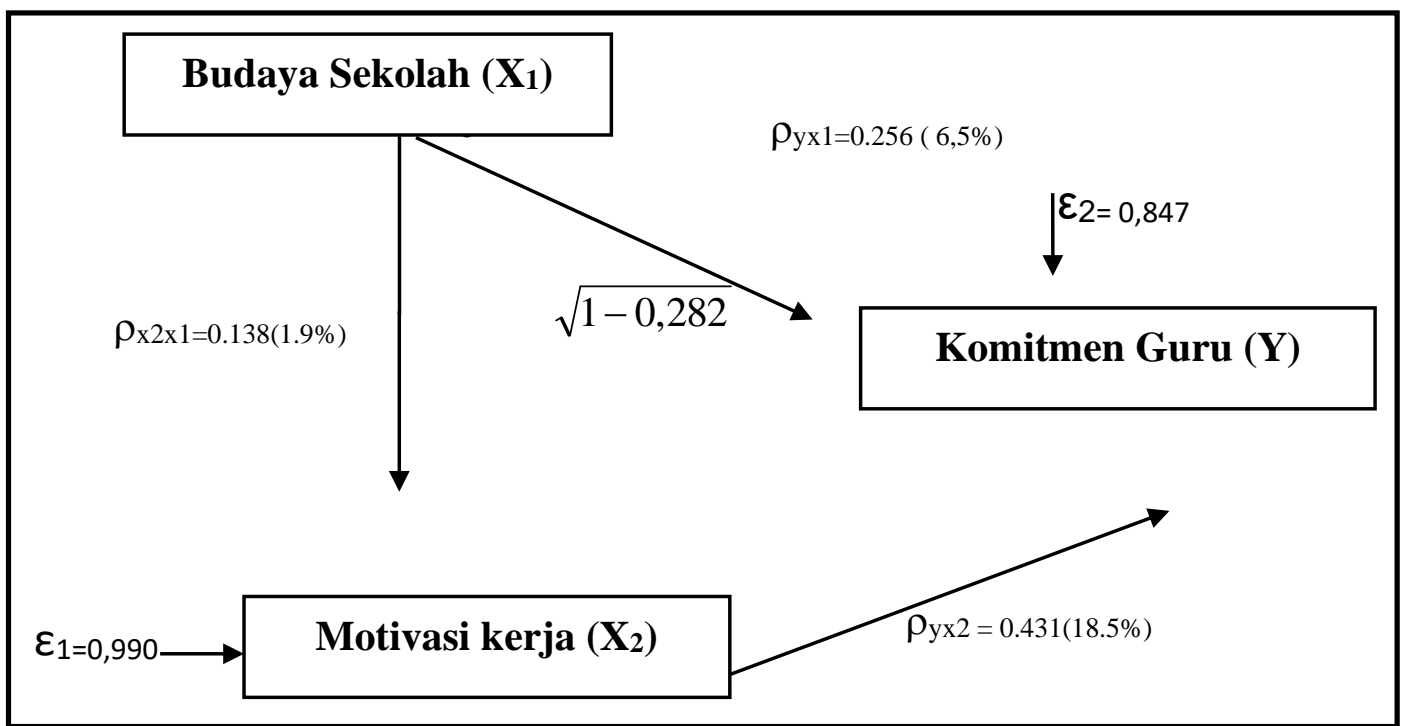

Gambar 2

Pengaruh Budaya Sekolah (X1)

dan Motivasi Kerja ( X2 ) terhadap Komitmen Guru (Y) 
Berdasarkan hasil perhitungan diperoleh koefisien jalur yang menunjukkan besarnya pengaruh antar variabel sebagai berikut

Tabel 3.Matrik koefisien jalur antara budaya sekolah $\left(X_{1}\right)$ dan motivasi kerja $\left(\mathrm{X}_{2}\right)$ terhadap komitmen guru $(\mathrm{Y})$

\begin{tabular}{|c|c|c|c|c|}
\hline & X1 & X2 & Y & X1X2 \\
\hline X1 & & $\mathbf{0 , 1 3 8}$ & $\mathbf{0 , 2 5 6}$ & \\
\hline X2 & $\mathbf{0 , 1 3 8}$ & & $\mathbf{0 , 4 3 1}$ & \\
\hline Y & $\mathbf{0 , 2 5 6}$ & $\mathbf{0 , 4 3 1}$ & & $\mathbf{0 , 2 8 2}$ \\
\hline X1X2 & & & 0,282 & \\
\hline
\end{tabular}

Hasil perhitungan dan hasil uji hipotesis ditunjukkan pada tabel 4 dibawah ini :

\section{Tabel 4}

Hasil perhitungan Koefisien jalur , Koefisien Determinan serta pengaruh antara variabel antara budaya sekolah $\left(X_{1}\right)$ dan motivasi kerja $\left(X_{2}\right)$ terhadap komitmen guru (Y)

\begin{tabular}{|c|c|c|c|c|}
\hline Variabel & $\begin{array}{l}\text { Koefisien } \\
\text { Jalur }\end{array}$ & Sig. & $\begin{array}{c}\text { Kesimpulan } \\
\text { Statistik }\end{array}$ & Pengaruh \\
\hline$X_{1}-X_{2}$ & 0,138 & 0.00 & $\begin{array}{l}\text { Signifikan } \\
\text { (Ho ditolak) }\end{array}$ & $1,9 \%$ \\
\hline $\mathrm{X}_{1}-\mathrm{Y}$ & 0.256 & 0.04 & $\begin{array}{l}\text { Signifikan } \\
\text { (Ho ditolak) }\end{array}$ & $6,5 \%$ \\
\hline $\mathrm{X}_{2}-\mathrm{Y}$ & 0.431 & 0.00 & $\begin{array}{l}\text { Signifikan } \\
\text { (Ho ditolak) }\end{array}$ & $18.5 \%$ \\
\hline $\mathrm{X}_{1}, \mathrm{X}_{2}-\mathrm{Y}$ & $\mathrm{R}^{2}=0,282$ & \multicolumn{2}{|c|}{$\mathrm{F}_{\text {tabel }}$ dan $\mathrm{t}_{\text {tabel }}(\alpha=0,05)$} & $28,2 \%$ \\
\hline$\varepsilon_{1}$ & 0,990 & - & - & $98,1 \%$ \\
\hline$\varepsilon_{2}$ & 0,847 & - & - & $71,8 \%$ \\
\hline
\end{tabular}

Sumber : Data olahan

\section{SIMPULAN DAN SARAN}

Simpulan

Dari hasil analisis penelitian yang telah dilakukan, dapat ditarik beberapa kesimpulan penelitian yaitu:

1. Hasil penelitian menunjukkan bahwa budaya sekolah mempunyai pengaruh positif terhadap motivasi kerja. Hal ini mengindikasikan bahwa budaya sekolah dapat meningkatkan motivasi kerja guru. Berdasarkan temuan penelitian ini dapat disimpulkan bahwa hipotesis penelitian yang menyatakan budaya 
sekolah berpengaruh terhadap motivasi kerja guru dapat diterima.

2. Hasil penelitian menunjukkan bahwa budaya sekolah mempunyai pengaruh positif terhadap komitmen guru. Hal ini mengindikasikan bahwa budaya sekolah dapat meningkatkan komitmen guru. Artinya hipotesis yang diajukan bahwa budaya sekolah berpengaruh terhadap komitmen guru dapat diterima.

3. Hasil penelitian menunjukkan bahwa motivasi kerja mempunyai pengaruh positif terhadap komitmen guru Sekolah Menengah Kejuruan di Kabupaten Kepulauan Meranti. Hal ini mengindikasikan dengan motivasi kerja yang tinggi maka dengan sendirinya akan meningkatkan komitmen guru. Berdasarkan temuan penelitian ini dapat disimpulkan bahwa hipotesis penelitian yang menyatakan motivasi kerja berpengaruh terhadap komitmen guru dapat diterima.

\section{Saran}

$$
\begin{array}{ll}
\text { Berdasarkan } & \text { temuan penelitian } \\
\text { dan implikasi penelitian, maka } \\
\text { disarankan : }
\end{array}
$$

1. Bagi kepala sekolah, peningkatan kemampuan kepala sekolah dalam

\section{DAFTAR PUSTAKA}

B.Uno,Hamzah, (2008), Teori Motivasi dan Pengukurannya, Analisis di Bidang Pendidikan .Jakarta ; PT Bumi Aksara.

Colquitt, Lepine,Wesson, (2009), Organizational Behavior ,Improving Performance and commitmen in the workplace. Newyork : Mc.Graw Hill Irwin .

Deal, Terrence E. dan Kent D. Peterson. (2009). Shaping School Culture: hal memberikan motivasi kerja pada guru agar budaya sekolah dijadikan pedoman dalam beradaptasi dengan lingkungan internal maupun eksternal sehingga guru giat bekerja dan berkomitmen tinggi demi kemajuan sekolah.

2. Bagi guru, agar terus meningkatkan komitmennya dengan menjadikan budaya sekolah sebagai pedoman untuk dapat mengembangkan potensinya dalam sekolah dan meningkatkan motivasi kerja sehingga bergairah dalam bekerja ,tidak akan menghindari tantangan dalam mencapai tujuan , mementingkan kualitas kerja dan mendapat pengakuan dalam mencapai tujuan sekolah.

3. Diharapkan kepada peneliti lain yang tertarik untuk meneliti komitmen guru dengan meneliti variabel lain yang secara konseptual diperkirakan berpengaruh terhadap peningkatan ataupun penurunan komitmen guru dalam ruang lingkup yang lebih luas, baik dengan menggunakan pendekatan penelitian kualitatif ataupun kuantitatif.

Pitfall, Paradoxes, and Promises. San Francisco: Josses-Bass.

Fred Luthans, (2006). Perilaku Organisasi .Yogyakarta : Andi

Gibson ,James L.et.al, (1985). Organisasi Perilaku, Struktur, Proses, Jakarta : Erlangga .

https://gurukreatif.wordpress.com/2010/ 05/19/5-budaya-di-sekolah-yangpatut-dikembangkan/ Agus Sampurno 
J.Winardi, (2002). Motivasi dan pemotivasian dalam manajemen . Jakarta :PT R.G Persada .

Kementerian Pendidikan Nasional, Badan penelitian dan pengembangan, Pusat kurikulum. 2011, Pengembangan pendidikan budaya dan karakter bangsa pedoman sekolah. Jakarta: Pusat Kurikulum

KomaruddinHidayat.(2010).“KulturSek olah".http://www.uinjkt.ac.id/inde x.php/ category-table/1456membangun-kultur-sekolah-.html.

Kurnia, Adi dan Bambang Qomaruzzaman. (2011). Membangun Budaya Sekolah Jakarta: Simbiosa Rekatama Media.

Koesmono,H Teman. (2013). "Pengaruh Motivasi, Budaya Organisasi, Kepemimpinan Transformasional, Transaksional terhadap Budaya Sekolah dan Komitmen Organisasional Guru Sekolah Menengah Atas Swasta Kristen Petra" . Jurnal Mitra Ekonomi dan Manajemen Bisnis.Vol 4 :2013,56-68. Fakultas Bisnis Unika Widya Mandala Surabaya

Lumban Tobing,Suyata. (2012) . "Pengaruh Budaya Ilmiah ,Disiplin dan Motivasi Kerja terhadap Komitmen Afektif Guru di SMP Negeri Kecamatan Lubuk Pakam Kabupaten Deli Serdang". Medan. Journal UNIMED Master . Vol. 22626 -809325020 Tesis. PPs Unimed.
Muhaimin ,et.al, (2009). Manajemen Pendidikan 'aplikasinya dalam penyusunan rencana pengembangan sekolah/madrasah,Jakarta: Kencana .

Nur Syam. (2011). "Membangun Kultur Sekolah". http://www.psbpsma.org/ content/blog/ 3460membangun-kultur-sekolah.

\section{Peraturan Pemerintah Republik Indonesia Nomor 46 Tahun 2011 ; tentang penilaian prestasi kerja pegawai negeri sipil.}

Peterson, Kent D. and Terrence E. Deal. (2009). The Shaping School Culture Filedbook. San Francisco: Josses-Bass

Purnama Sari,Ika .(2014) . Persepsi guru tentang budaya sekolah pada SMA Negeri di Kabupaten Lima Puluh Kota,Jurnal Administrasi Pendidikan, vol 2: 315-831

Raharjo,Pono.(2013). Manajemen Budaya Sekolah SMP Negeri 1 Kajen

KabupatenPekalongan.http://Jour nal.unnes.ac.id/sju/index.php/edu man .

Riduwan dan Engkos Achmad Kuncoro, (2012). Path Analysis (analisis Jalur),Bandung : Alfabeta .

Robbins ,Stephen P,dan Mary Coulter, (1999). Manajemen ,Jakarta : PT Prenhalindo .

Romli, khomsahrial, (2011). Komunikasi organisasi, Jakarta : PT Grasindo. 
Schumk,D.H.et.al, (2008). Motivation in Education.New Jersey, Prentice Hall.

Siregar, Astri Novia. (2014). "Pengaruh Budaya Sekolah, Kecerdasan Emosional, dan Pengelolaan Stress Kerja terhadap Komitmen Organisasi Guru Sekolah Menengah Atas Kabupaten Padang Lawas". Tesis, Medan: Program Pascasarjana Universitas Negeri Medan.

Sobirin,Achmad, (2007). Budaya Organisasi Pengertian, Makna dan Aplikasinya dalam Kehidupan Organisasi . Yogyakarta : Sekolah Tinggi Ilmu Manajemen YKPN.

Sopiah. (2008). Perilaku Organisasi. Yogyakarta : Andi .

Soetopo,Hendyat, (2010). Perilaku Organisasi,Teori dan Praktik dalam Bidang Pendidikan . Bandung: PT Remaja Rosdakarya.
Shapiro, Seth. Wise Skills: Schoolwide Implementation. Santa Cruz: www. wiseskills.com

Sudrajat,Ajat .(2015). Membangun Budaya Sekolah Berbasis Karakter Terpuji ,diakses pada tanggal 6 Maret 2015 jam 4:10 PM

Sumardi . (2013). “ Pengaruh Budaya Organisasi , Motivasi dan Disiplin Kerja terhadap Komitmen Organisasi Pegawai Dinas Pendidikan Kabupaten/Kota Pemekaran di Provinsi Riau". Jurnal Manajemen Pendidikan . vol. 1,hlm. 1-14.

Surbakti, Raisah. (2011). “ Pengaruh Motivasi, Kepribadian, dan Budaya Sekolah terhadap Komitmen Guru Madrasah Aliyah Negeri Padang Sidimpuan". Tesis , Medan: Program Pascasarjana Universitas Negeri Medan.

Steven P.Robbins dan Timoty Judge , (2011).Organizational Behavior . 13 Th Edition ,New Jerssey ;Paerson Education,Inc. 